\title{
İnternal kök rezorpsiyonunun MTA ile tedavisi: Olgu bildirimi
}

\author{
Tuba Gök ${ }^{1}$, İsmail Davut Çapar ${ }^{1}$
}

Selcuk Dental Journal, 2014; 2: 66-70

Başvuru Tarihi: 18 Kasım 2013 Yayına Kabul Tarihi: 31 Ocak 2014

\section{Treatment of internal root resorption with MTA: A case report}

In this case report the treatment and 9 months follow up of maxillary lateral incisor is presented which has an internal resorption with a periradicular lesion. Root canal treatment performed using mineral trioxide aggregate. At 9 months follow-up the tooth was asymptomatic and radiographically showed repair of the lesion and consequently any additional treatment procedure was not applied.

\section{KEY WORDS}

Cone beam computed tomography, MTA, root resorption

İnternal rezorbsiyon (IR), pulpada üretilen granülasyon dokusuna komşu dentinin iç yüzeyinde oluşan rezorbsiyon olarak karakterize edilir (Trope ve ark 2002). Internal enflamatuar kök rezorbsiyonunda diş sert dokularının yıkım olayı odontoklastik aktivite ile olur (Haapasalo ve ark 2006, Patel ve ark 2010). iR ile ilişkili pulpal granulasyon dokusunun kaynağına yönelik çeşitli teoriler olsa da en tutarlı açıklama, enfekte koronal pulpa boşluğunun neden olduğu pulpa dokusunun enflamasyonu veya travmadır (Trope ve ark 2002). Bazı araştırmacılara göre ise IR' un etyolojisi tam olarak bilinmemekle birlikte travma, çürük, periodontal hastalıklar, ortodontik tedaviler, bruksizm, travmatik kavite preparasyonu gibi durumlar iR' a neden olabilir (Çalışkan 2006).

Klinik olarak IR genellikle asemptomatiktir ve rutin radyografiler ile rastlantısal olarak saptanır (Haapasalo ve Endal 2006). Rezorbsiyon kuron veya kökün dışına doğru gelişir ve bir perforasyon oluşursa, metaplastik pulpa ağız sıvılarıyla temasa geçebilir ve pulpa nekrozu veya ağrı oluşabilir, hatta periodontal lezyon gelişebilir (Trope 1998). Eğer lezyon tespit edilmeyip tedavi edilmeden kalırsa, potansiyel olarak büyür ve kök yüzeyini içeriden perfore eder. Yeterince erken tespit edildiğinde ise tedavisi ve dişin uzun süreli prognozu iyi olur. Diş dokusundan önemli miktarda yıkım olursa veya rezorbsiyon marjinal kemiğe yaklaşırsa dişi zayıflatır ve tedavinin prognozu olumsuz etkilenir (Gabor ve ark 2012).

Kök kanal sistemindeki kompleks düzensizlikler, özellikle îR defektleri, kök kanal temizliği ve dolumu için teknik zorluklar oluşturmaktadır. Bu düzensizliklerdeki organik debrisin ve bakterilerin kalması, endodontik tedavinin uzun dönem başarısını etkileyebilmektedir (Goldberg ve ark 2000). Bu sebeple kök kanal boşluğunun tamamıla doldurulması in vakalarında önemle belirtilmiştir (Frank ve ark 1973).

Orijinalinde cerrahi olarak kök ucu dolgu materyali olarak geliştirilen mineral trioksit agregat (MTA), pulpa kuafajı (Torabinejad ve ark 1996), pulpotomi (Salako ve ark 2003), perforasyon tamiri (Main ve ark 2004), açık apeksli travmatize dişlerin tedavisi (Bakland 2000) ve kök rezorbsiyonlarının tedavisi (Hsien ve ark 2003) gibi bazı klinik uygulamalar için de başarılı olarak kullanılmaktadır. in vakalarında defektin uygun materyal ile restore edilmesi önem taşımaktadır. MTA, üstün tıkaçlama özelliği (Torabinejad ve ark 1993), biyouyumluluğu (Torabinejad ve ark 1995, Koh ve ark 1998), fibroblastik stimulasyonu (Guven ve ark 2007) ve antimikrobiyal aktivitesi (Zhang ve ark 2009) ile uygun bir perforasyon tamir materyali olarak öne sürülmüştür. Ayrıca MTA, yüzeyinde yeni sement oluşumuna izin vererek periodontal iyileşmeye yardımcı bir ortam sağlamaktadır (Holland ve ark 2001). iR bulunan dişlerin kırılma direnci sağlam dişlere göre azalmış olmakla birlikte,

\footnotetext{
${ }^{1}$ İzmir Katip Çelebi Üniversitesi Diş Hekimliği Fakültesi Endodonti Anabilim Dalı, İzmir
} 
deneysel immatür diş modelleri ile yapılan bir çalışmada MTA'nın dişlerde kırılma direncini de artırdığı belirtilmiştir (Bortoluzzi ve ark 2007).

$\mathrm{Bu}$ olgu bildiriminin amacı, IR tespit edilen üst sağ lateral dişte rezorbsiyon alanın MTA kullanılarak tıkanması ve ardından endodontik prosedürler ile tedavisinin bitirilerek prognozunun sunulmasıdır.

Yirmi altı yaşındaki bir erkek hasta diş eksiklikleri nedeniyle kliniğimize başvurdu. Hastadan alınan anamnezde herhangi bir sistemik hastalığı olmadığı, düzenli olarak bir ilaç kullanmadığı, on sene öncesinde travma hikayesi olduğu ve travma sonrası üst sol santral dişinin çekildiği öğrenildi. Alınan radyografide üst sağ santral dişte apikal radyolusensi, üst sağ lateral dişte ise apikal radyolusensi ile birlikte internal kök rezorbsiyonu tespit edildi (Resim 1). Klinik muayenede her iki dişte de perküsyon ve palpasyonda ağrı mevcut değildi. Periodontal dokularda fistül ağzı ve ilgili dişlerde mobilite gözlemlenmedi.

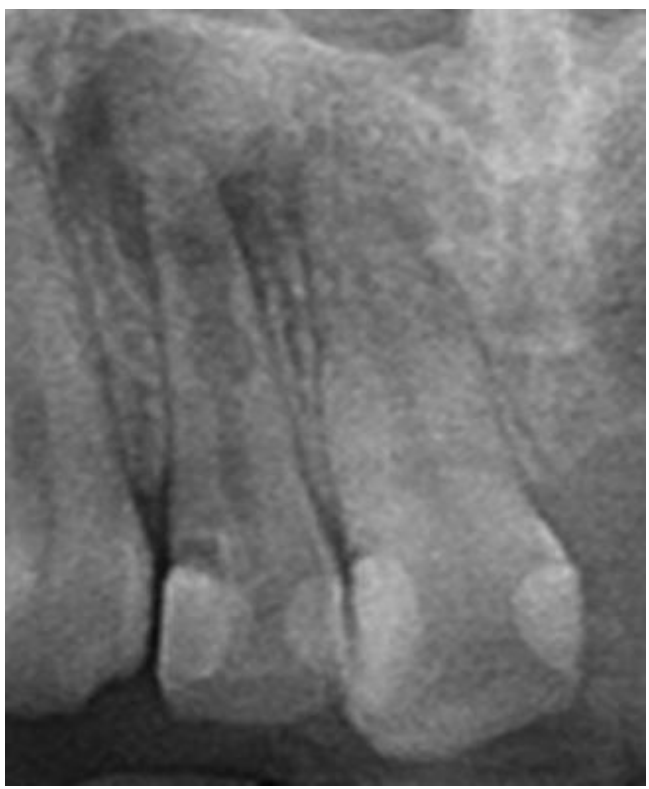

Resim 1.

İnternal kök rezorbsiyonu ve apikal radyolusensinin görüldüğü teşhis radyografisi
Üst sağ lateral dişte tedaviye başlamadan önce perforasyon alanının sınırlarını tespit edebilmek için hastadan konik ışınlı bilgisayarlı tomografi [(KIBT) (NewTom 5G(®), QR, Verona, İtalya)] ile $0.15 \mathrm{~mm}$ voksel boyutunda ve $1.0 \mathrm{~mm}$ kesit kalınlığında görüntüler alındı. Görüntüler incelendikten sonra dişin apikal ve orta üçlüsünde geniş IR alanları olduğu tespit edildi (Resim 2). Daha sonra ilk olarak rezorbsiyon olan dişte kök kanal tedavisine başlandı. Elmas rond frezle giriş kavitesi açıldıktan sonra 60 numara K tipi kanal eğesi (MANI Inc, Utsunomiya, Japonya) kullanılarak kanal boyu radyolojik olarak belirlendi. Çevresel eğeleme yapılarak kök kanalları şekillendirildi ve her eğe arasında $5 \mathrm{~mL} \% 1$ ' lik $\mathrm{NaOCl}$ ile irrigasyon işlemi yapıldı. Final irrigasyonu 5 $\mathrm{mL} \% 17^{\prime}$ lik EDTA, ardından $5 \mathrm{~mL}$ steril salin ve $3 \mathrm{~mL} \% 2$ ' lik klorheksidin ile tamamlandı. Kanallar paper point ile kurulandı. MTA (Angelus, Londrina, PR, Brezilya) üretici firmanın tavsiyeleri doğrultusunda hazırlandı ve kanala uygun bir plugger ile kanal içine gönderilerek vertikal kondansasyonu sağlandı. Daha sonra röntgen çekilerek MTA nın apikal ile birlikte rezorbsiyon alanına adaptasyonunun sağlanıp sağlanmadığı kontrol edildi. MTA nın sertleşmesi için kanal içerisine steril su ile nemlendirilen paper point konuldu ve Equia cam iyonomer (GC, Tokyo, Japonya) ile geçici dolgusu yapıldı. Hasta bir gün sonra çağırılarak paper point çıkarıldı ve kanal dolgusunun geri kalan kısmı System B (Anonim 2009) ısı kaynağı ile devamlı ısıyla obturasyon tekniği kullanılarak dolduruldu. Kuron restorasyonu kompozit (Tetric N Ceram Ivoclar Vivadent Scann, Lihtenştayn) ile yapıldı. Bir hafta sonra üst sağ santral dişe kanal tedavisi yapıldı, periapikal radyografisi alındı ve hasta 9 ay sonrası için kontrole çağrıldı. Dokuz ay sonraki yapılan ağız içi muayene ve radyografik tetkiklerde ilgili dişlerde herhangi bir semptom olmadığı ve radyografik olarak lezyonun iyileştiği tespit edildi (Resim 3).
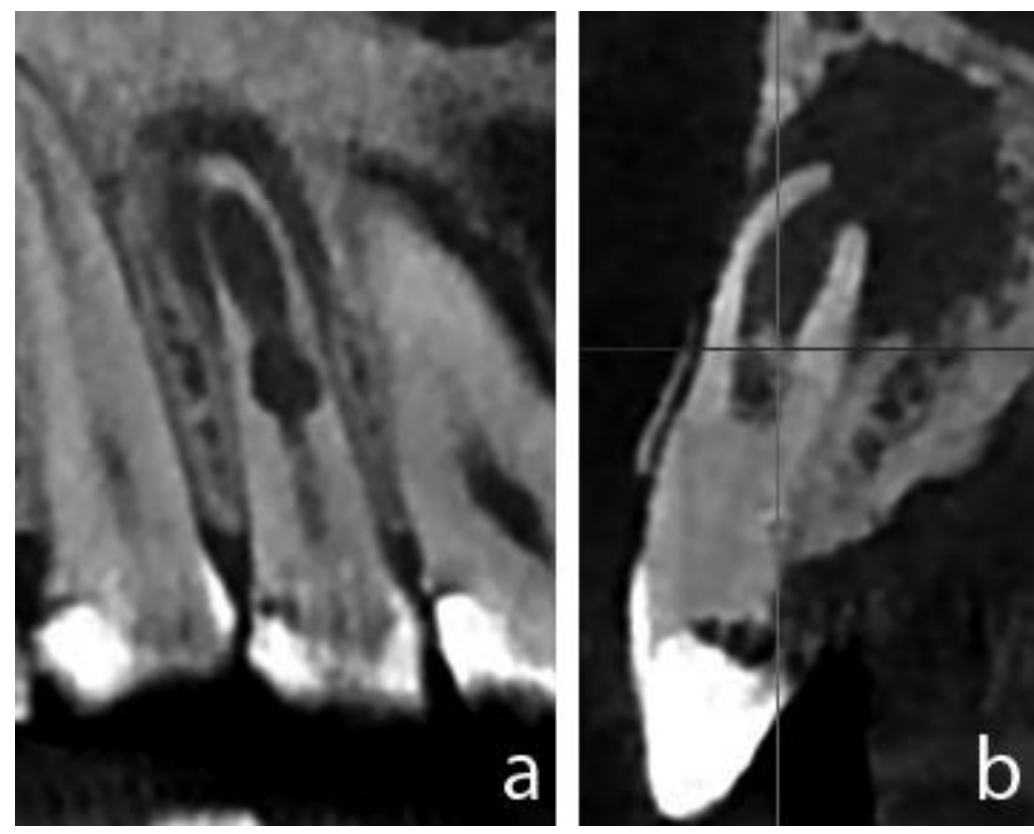

Resim 2.

Rezorbsiyon alanının KIBT yöntemi ile koronal (a) ve sagital görüntüleri (b). 

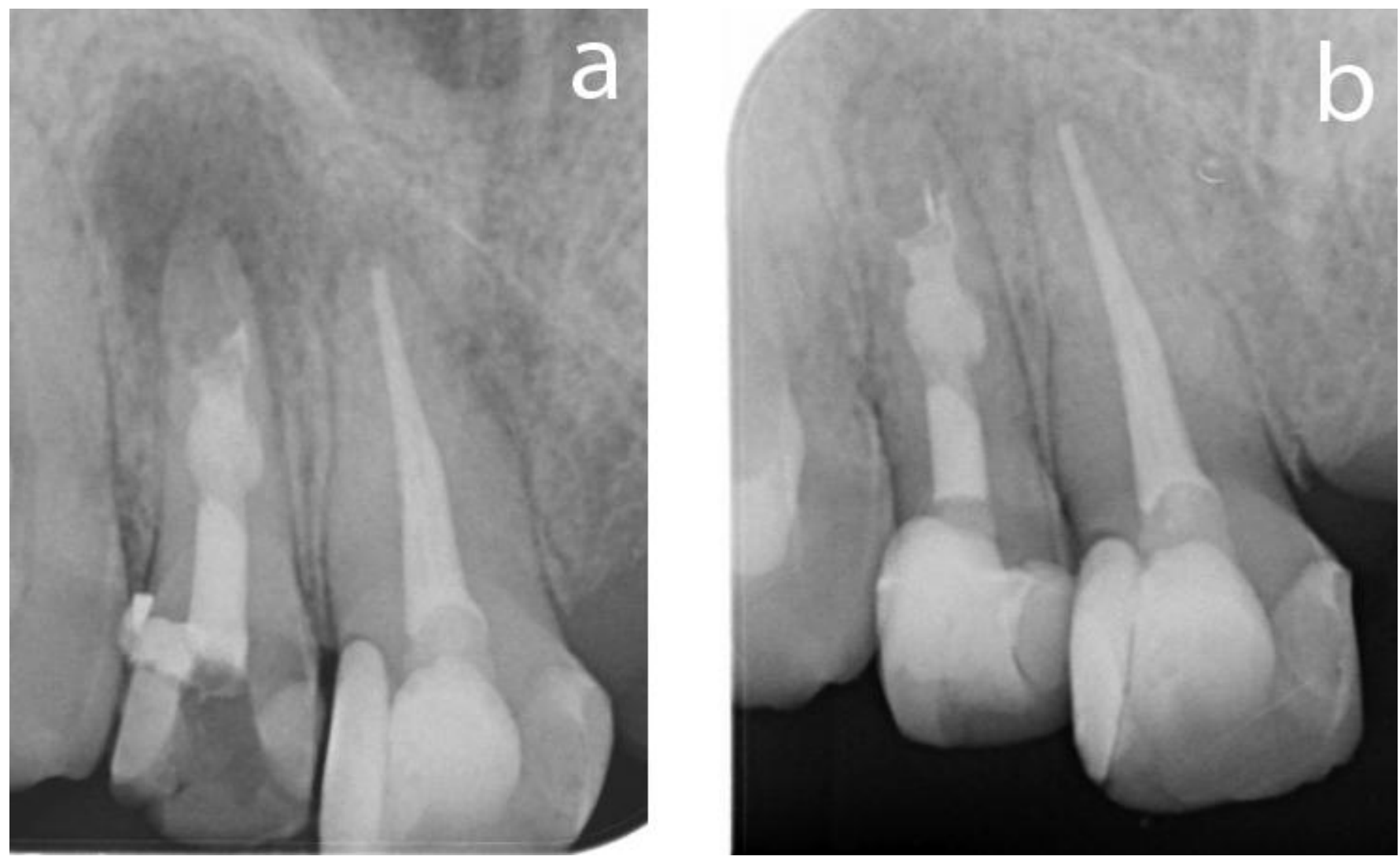

$\operatorname{Resim} 3$.

Kanal tedavisinden hemen sonra alınan periapikal radyografi (a), tedaviden 9 ay sonra alınan kontrol radyografisinde apikal lezyonun iyileştiği görülmektedir (b)

Genellikle asemptomatik olan iR' un teşhisi çoğu zaman rastlantısal olarak yapılmaktadır. Teşhisi yapılmayan IR olgularında defekt büyüyerek periodontal alana perfore olabilmektedir. Böyle olgularda kalan dental dokuların zayıflaması ve olası periodontal ilişkiden dolayı endodontik tedavinin prognozu kötü etkilenebilmektedir (Torabinejad ve ark 2006, Silveira ve ark 2009). Bu olgu sunumunda uzun yıllar önce maksiller anterior bölgede travma hikayesi olan hastada iR gelişmiştir ve MTA ile rezorbsiyon bölgesi doldurulduktan sonra kök kanal tedavisi yapılarak 9 aylık takipte iyileşme sağlandığı gözlemlenmiştir.

IR birkaç ay gibi kısa bir sürede gelişebileceği gibi uzun yıllar boyunca yavaş bir şekilde de gelişimi devam edebilir (Smulson ve Siareski 1996). Bazı çalışmalar rutin radyografilerin her zaman güvenilir bir lezyon varlığını ortaya koymadığını rapor etmiş olup lezyonun gerçek boyutu ve anatomik yapılarla olan ilişkisini tam olarak göstermediğini ortaya koymuşlardır (Barbat ve ark 1998, Gao ve ark 2010). Son zamanlarda ekstra oral üç boyutlu görüntüleme tekniği olan KIBT tekniği popülarite kazanmıştır. KIBT tekniği, düşük radyasyon dozu ile hekime üç boyutlu görüntü elde etme olanağı sunmaktadır. Böylece rezorbsiyon alanının gerçeğe yakın boyutlarda daha ayrıntılı bir şekilde incelenmesi sağlanmaktadır (Arslan ve ark 2011). Bu olgu sunumunda da tedaviden önce hastadan KIBT ile görüntü alınmış ve rezorbsiyon alanı incelenerek tedavi planlaması yapılmışırı.

Rezorbsiyon defektlerinin tam bir şekilde temizlenmesi için teknik zorlukların olmasından dolayı (Goldberg ve ark 2000), IR vakalarında başarılı bir tedavinin önemli amaçlarından biri de kök kanal boşluğunun tamamen doldurulabilmesi olmuştur (Frank ve Weine 1973). Rezorbe olmuş alanı tamamen doldurabilmek için dolgu malzemesinin akışkan olması gerekmektedir. Güta-perka, endodontide en yaygın kullanılan dolgu malzemesi olup bu malzemenin ısı ile yumuşatılarak akışkan bir kıvamda kullanıldığı sıcak güta-perka teknikleri bulunmaktadır. Bu teknikler kullanılarak yapılan çalışmalarda rezorbsiyon alanının başarılı bir şekilde doldurulduğu rapor edilmiştir (Stamos ve ark 1986, Wilson ve ark 1987, Goldberg ve ark 2000, Gencoglu ve ark 2008). System B, sıcak güta-perka tekniği olup bu vakada MTA ile apikaldeki rezorbsiyon bölgesi doldurulduktan sonra geri kalan kök kanal boşluğunun doldurulması için kullanılmıştır. 
Kök duvarının perfore olduğu durumlarda perforasyonu kapatmak için, üstün kapama özelliği, kan varlığında sertleşebilmesi, bakterisid etkisi ve biyouyumluluğu (Aminoshariae ve ark 2003) gibi avantajlarından dolayı MTA' nın kullanımı tavsiye edilmektedir (Patel ve ark 2010). Ayrıca MTA, periodontal ataşmanı rejenere etmesi ve osteogenez ve sementogenezi indüklemesi özellikleri ile de kök perforasyonlarının tedavisi için uygun bir malzemedir (Lee ve ark 1993, Koh ve ark 1998). Üst kesici dişlerde periodontal alana perfore olmuş iR defekti bulunan birçok olguda, perforasyon alanın ortograd yoldan MTA ile doldurulduğu ve iyileşme sağlandığı belirtilmiştir (Jacobovitz ve ark 2008, Mohammadi ve ark 2012, Nunes ve ark 2012, Paul ve ark 2013). Bu olgu bildiriminde de perforasyon alanının kapatılması amacıyla MTA ortograd yoldan uygulanmıştır. Fakat tedavi sonrası yapılan radyografik incelemede apikalde bulunan defekt alanının tam olarak MTA ile kapatılamadığı tespit edilmiştir. Buna rağmen ilgili dişin kısa dönem takibinde lezyonun radyografik olarak iyileşme bulguları gösterdiği saptanmıştır.

Geniş rezorbsiyon alanlarının bulunduğu bu tür olgularda periradiküler lezyonun tekrar gelişme intimali göz önünde bulundurularak uzun dönem takip gerekmektedir. Olguda başarısızık olması

\section{Internal kök rezorbsiyonunun MTA ile tedavisi: Olgu bildirimi}

Bu vaka raporunda internal rezorbsiyon ve periradiküler lezyona sahip üst sağ lateral dişin mineral trioksit agregat kullanılarak yapılan kök kanal tedavisinin 9 aylık takibi sunulmaktadır. Tedaviden 9 ay sonra yapılan muayenede ilgili dişin asemptomatik olduğu ve lezyonun radyografik olarak iyileştiği gözlendi, buna bağıı olarak herhangi bir ilave tedavi prosedürü uygulanmadı.

\section{ANAHTAR KELIMELER}

Konik ışınlı bilgisayarlı tomografi, kök rezorbsiyonu, MTA

\section{KAYNAKLAR}

Anonim 2009. http://www.sybronendo.com/ Erişim tarihi 06.07.2014

Aminoshariae A, Hartwell GR, Moon PC, 2003. Placement of mineral trioxide aggregate using two different techniques. J Endod, 29, 679-682.

Arslan S, Tınaz C, Kayaoğlu G, 2011. Eksternal servikal kök rezorpsiyonu: olgu bildirimi. GÜ Diş Hek Fak Derg, 28, 35-39.

Bakland LK, 2000. Management of traumatically injured pulps in immature teeth using MTA. J Calif Dent Assoc, 28, 855-858.

Barbat J, Messer HH, 1998. Detectability of artificial periapical lesions using direct digital and conventional radiography. J Endod, 24, 837-842.

Bortoluzzi EA, Souza EM, Reis JM, Esberard RM, Tanomaru-Filho M, 2007. Fracture strength of bovine incisors after intra-radicular treatment with MTA in an experimental immature tooth model. Int Endod J, 40, 684-691.

Çalışkan MK, 2006. Diş rezorpsiyonları, In: Endodontide Tanı ve Tedaviler, Ed; Çalışkan MK, İkinci Baskı baskı, Nobel Yayınevi, İstanbul, Türkiye, pp; 180-181.

Frank AL, Weine FS, 1973. Nonsurgical therapy for the perforative defect of internal resorption. J Am Dent Assoc, 87, 863-868.

Gabor C, Tam E, Shen Y, Haapasalo M, 2012. Prevalence of internal inflammatory root resorption. J Endod, 38, 24-27.

Gao Y, Haapasalo M, Shen Y, Wu H, Jiang H, Zhou $X, 2010$. Development of virtual simulation platform for investigation of the radiographic features of periapical bone lesion. J Endod, 36, 1404-1409.

Gencoglu N, Yildirim T, Garip Y, Karagenc B, Yilmaz $H$, 2008. Effectiveness of different gutta-percha techniques when filling experimental internal resorptive cavities. Int Endod J, 41, 836-842.

Goldberg F, Massone EJ, Esmoris M, Alfie D, 2000. Comparison of different techniques for obturating experimental internal resorptive cavities. Endod Dent Traumatol, 16, 116-121.

Guven G, Cehreli ZC, Ural A, Serdar MA, Basak F, 2007. Effect of mineral trioxide aggregate cements on transforming growth factor beta1 and bone morphogenetic protein production by human fibroblasts in vitro. J Endod, 33, 447-450.

Haapasalo M, Endal U, 2006. Internal inflammatory root resorption: the unknown resorption of the tooth. Endod Topics, 14, 60-79. 
Holland R, Filho JA, de Souza V, Nery MJ, Bernabe $P F$, Junior ED, 2001. Mineral trioxide aggregate repair of lateral root perforations. J Endod, 27, 281-284.

Hsien HC, Cheng YA, Lee YL, Lan WH, Lin CP, 2003. Repair of perforating internal resorption with mineral trioxide aggregate: a case report. J Endod, 29, 538539.

Jacobovitz M, de Lima RK, 2008. Treatment of inflammatory internal root resorption with mineral trioxide aggregate: a case report. Int Endod J, 41, 905-912.

Koh ET, McDonald F, Pitt Ford TR, Torabinejad M, 1998. Cellular response to Mineral Trioxide Aggregate. J Endod, 24, 543-547.

Lee SJ, Monsef M, Torabinejad M, 1993. Sealing ability of a mineral trioxide aggregate for repair of lateral root perforations. J Endod, 19, 541-544.

Main C, Mirzayan N, Shabahang S, Torabinejad M, 2004. Repair of root perforations using mineral trioxide aggregate: a long-term study. J Endod, 30, 80-83.

Mohammadi Z, Yazdizadeh M, Shalavi S, 2012. NonSurgical Repair of Internal Resorption with MTA: A Case Report. Iran Endod J, 7, 211-214.

Nunes E, Silveira FF, Soares JA, Duarte MA, Soares SM, 2012. Treatment of perforating internal root resorption with MTA: a case report. J Oral Sci, 54, 127-131.

Patel S, Ricucci D, Durak C, Tay F, 2010. Internal root resorption: a review. J Endod, 36, 1107-1121.

Paul B, Dube K, Rai A, Randhelia S, 2013. MTA as Apical Filling Material In Internal Resorption. IOSRJDMS, 5, 35-37.

Salako N, Joseph B, Ritwik P, Salonen J, John P, Junaid TA, 2003. Comparison of bioactive glass, mineral trioxide aggregate, ferric sulfate, and formocresol as pulpotomy agents in rat molar. Dent Traumatol, 19, 314-320.

Silveira FF, Nunes E, Soares JA, Ferreira CL, Rotstein I, 2009. Double 'pink tooth' associated with extensive internal root resorption after orthodontic treatment: a case report. Dent Traumatol, 25, 43-47.

Smulson MH, Siareski S, 1996. Histophysiology and diseases of the dental pulp. In: Endodontic Therapy, Ed; Weine FS, Beşinci Baskı, St. Louis, Mosby, pp: 84-165.

Stamos DE, Stamos DG, 1986. A new treatment modality for internal resorption. J Endod, 12, 315319.
Torabinejad M, Goodacre CJ, 2006. Endodontic or dental implant therapy: the factors affecting treatment planning. J Am Dent Assoc, 137, 973-977.

Torabinejad M, Hong CU, Pitt Ford TR, Kettering JD, 1995. Cytotoxicity of four root end filling materials. J Endod, 21, 489-492.

Torabinejad M, Pitt Ford TR, 1996. Root end filling materials: a review. Endod Dent Traumatol, 12, 161178.

Torabinejad M, Watson TF, Pitt Ford TR, 1993. Sealing ability of a mineral trioxide aggregate when used as a root end filling material. J Endod, 19, 591595.

Trope M, 1998. Root resorption of dental and traumatic origin: classification based on etiology. Pract Periodontics Aesthet Dent, 10, 515-522.

Trope M, Chivian N, Sigurdsson A, Vann WFJ, 2002. Traumatic injuries, In: Pathways of the Pulp, Ed; Cohen S, Burns RC, Sekizinci Baskı, St. Louis, Mosby, pp; 603-651.

Wilson PR, Barnes IE, 1987. Treatment of internal root resorption with thermoplasticized gutta-percha. A case report. Int Endod J, 20, 94-97.

Yazışma Adresi:

Arş.Gör.Tuba GÖK

İzmir Kâtip Çelebi Üniversitesi

Diş Hekimliği Fakültesi Endodonti AD

35000, İzmir

Tel: +90 (232) 3254040 (dahili: 2400)

Fax:+90 (232) 3252535

E-mail: tuba3788@hotmail.com 